\title{
Clinical Reasoning: Multifocal neuropathies in a patient with Waldenstrom macroglobulinemia and prior borreliosis
}

Benjamin C. Cox, MD, Michelle L. Mauermann, MD, Elitza S. Theel, PhD, and Michel Toledano, MD

Neurology ${ }^{\circledR}$ 2020;95:44-48. doi:10.1212/WNL.0000000000009741

\author{
Correspondence \\ Dr. Cox \\ Cox.Benjamin@mayo.edu
}

\section{Section 1}

A 77-year-old man presented with 1 week of back pain, night sweats, confusion, jaundice, and pruritus with patchy, blanchable erythematous lesions over his trunk (figure 1). Neurologic examination was normal, but a lumbar spine MRI showed diminished bone marrow signal. $\mathrm{He}$ was thrombocytopenic $\left(13 \times 10^{9} / \mathrm{L}\right)$ and anemic $(7.2 \mathrm{~g} / \mathrm{dL})$ with an immunoglobulin M (IgM) kappa monoclonal gammopathy and bone marrow biopsy consistent with Waldenstrom macroglobulinemia (WM). He was initiated on $60 \mathrm{mg}$ prednisone daily and rituximab. Skin biopsy revealed nonspecific dermal edema with perivascular inflammation. Two weeks into admission, he developed left lower motor neuron facial droop, and was kept on the prednisone started 2 days prior for his WM. Shortly after that, it was noted that his Borrelia burgdorferi enzyme immunoassay (EIA) screen and supplemental B burgdorferi IgM immunoblot were positive, while the immunoglobulin $\mathrm{G}$ immunoblot was negative. Three weeks later, his facial palsy had resolved, but given extensive tick exposure history, he was treated with 3 weeks of doxycycline. CSF collection was deferred due to thrombocytopenia.

Nine months later, the patient presented to neurology with 3 weeks of progressive left ptosis, bilateral upper extremity weakness, and neuropathic pain in a C5 distribution. MRI head and cervical spine were unremarkable. CSF showed a mildly elevated protein of $65 \mathrm{mg} / \mathrm{dL}$ with normal cell count and glucose, 7 unique oligoclonal bands, and negative cytology. Because of the prior Lyme disease (LD), an LD CSF antibody index (AI) was performed, which was elevated at

Figure 1 Multifocal, blanchable, erythematous patches over the trunk, some with a dusky center

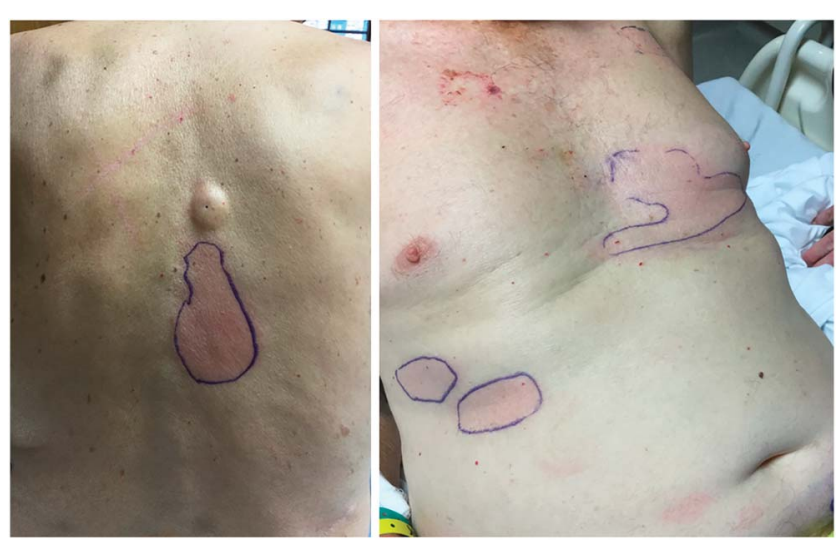

From the Departments of Neurology (B.C.C., M.L.M., M.T.) and Laboratory Medicine and Pathology (E.S.T.), Mayo Clinic, Rochester, MN.

Go to Neurology.org/N for full disclosures. Funding information and disclosures deemed relevant by the authors, if any, are provided at the end of the article. 
6.0 (normal 0.6-1.2). He received IV ceftriaxone, but his condition declined, with the patient developing binocular horizontal diplopia and dysphagia, prompting admission.

Examination showed left ptosis, a pupil-sparing third nerve palsy, and left lower motor neuron facial palsy. Muscle testing revealed right greater than left weakness (4/5 range) in the deltoids, biceps, triceps, wrist and digit extensors, and interossei. In the lower extremities, the patient had $4 / 5$ weakness in L5 innervated muscles. Reflexes were absent in the right upper limb and left triceps with hypoactive left biceps and brachioradialis reflexes. Ankle reflexes were absent with trace response at the knees. Toes were downgoing. He had mild lengthdependent sensory loss in the feet with relative preservation in upper extremities. Electrodiagnostic studies showed a diffuse axonal-predominant sensorimotor polyradiculoneuropathy in the cervical segments and left L5 nerve root. MRI brain, orbits, and cervical spine were negative, but lumbar MRI showed thickening of the nerve roots with associated enhancement (figure 2A). Antineutrophil cytoplasmic antibodies, antinuclear antibodies, lactate dehydrogenase, HIV serology, repeat LD serology, and a paraneoplastic panel in serum and CSF were negative. Erythrocyte sedimentation rate was $114 \mathrm{~mm} / \mathrm{h}$ and C-reactive protein was $87.4 \mathrm{mg} / \mathrm{L}$.

\section{Questions for consideration:}

1. Where do you localize this process?

2. What is your differential diagnosis?

3. Did the patient have LD and is his latest presentation consistent with neuroborreliosis?

GO TO SECTION 2 


\section{Section 2}

The patient presented with subacute weakness and diplopia. His examination, with patchy asymmetric weakness and hyporeflexia in multiple nerve root distributions, as well as relatively preserved sensation in spite of radicular pain, was suggestive of a polyradiculoneuropathy, which was confirmed by EMG. He also had multiple cranial neuropathies.

The patient's first neurologic symptom was an isolated left-sided facial palsy occurring 2 weeks into his original presentation. The differential diagnosis then included neurologic involvement of the newly diagnosed lymphoproliferative disorder (Bing-Neel syndrome), infectious neuritis, or idiopathic facial palsy. Given possible exposure in a Lyme-endemic region, LD testing was obtained, which demonstrated a positive LD EIA screen and IgM immunoblot, with a negative IgG immunoblot, suggesting acute infection. Diagnostic testing for $\mathrm{LD}$ relies on detection of antibodies to $B$ burgdorferi using the standard 2-tiered testing algorithm, which starts with an initial EIA or immunofluorescence assay. ${ }^{1}$ Positive samples require supplemental anti- $B$ burgdorferi IgM or IgG immunoblot testing, depending on the duration of symptoms. The Centers for Disease Control and Prevention (CDC) requires detection of IgM antibodies to at least 2 of 3 antigens and detection of IgG class antibodies to at least 5 of 10 antigens to be considered positive. Importantly, an isolated positive IgM immunoblot result is only meaningful during the first 4 weeks of symptoms. For symptoms longer than 4 weeks, only the IgG immunoblot should be considered to determine the presence or absence of LD. Our patient met CDC criteria on initial presentation as he presented within 4 weeks of symptom onset. Although he did not have the classic erythema migrans, his rash had multiple red lesions with dusky centers, which is not uncommon in early borreliosis and spontaneous recovery without treatment has been reported. ${ }^{2}$

When the patient later presented with progressive deficits and a positive LD CSF AI, neuroborreliosis was considered. The problem with this diagnosis is the time course. Whereas his initial presentation with left-sided Bell palsy, rash, and a positive serum LD IgM could be consistent with neuroborreliosis, his symptoms had resolved and he had completed appropriate antibiotics. Neuroborreliosis is almost always monophasic and so emergence of new symptoms 9 months later would more likely be caused by reinfection, if truly due to LD. It is important to remember that the LD CSF AI can remain positive for years following adequate treatment. ${ }^{3}$ Detection of $B$ burgdorferi by real-time PCR (RT-PCR) in CSF would provide definitive evidence of active infection; however, a negative RT-PCR does not rule out infection, due to low sensitivity. ${ }^{4}$ Thus recent Infectious Diseases Society of America draft guidelines for neuroborreliosis recommend against using RT-PCR for diagnosis. ${ }^{4}$

Acute inflammatory demyelinating polyradiculoneuropathy (AIDP) is another consideration and the patient's CSF did demonstrate cytoalbuminologic dissociation. The asymmetric presentation and electrodiagnostic studies demonstrating primarily axonal changes would be atypical, but could be present in axonal forms of AIDP. Similarly, anti-myelin-associated glycoprotein peripheral neuropathy usually presents as a symmetric, primarily sensory demyelinating neuropathy with ataxia and tremor. Vasculitic neuropathies are usually multifocal and workup for systemic vasculitis was negative. Paraneoplastic disease was unlikely with negative antibodies in serum and CSF.

Although root enhancement on MRI can be seen with immune-mediated polyradiculoneuropathies, this is typically more diffuse; our patient's pattern of focal enhancement is suggestive of an infiltrative process, such as a neoplasm (figure 2, A-C). Neurosarcoidosis can also focally enhance; however, in this context, direct peripheral nerve involvement of lymphoma (neurolymphomatosis) is more likely.

Waldenstrom macroglobulinemia rarely infiltrates the peripheral nervous system, ${ }^{5}$ but other lymphomas can present with multiple peripheral and cranial neuropathies. About 10\% of patients with low-grade lymphomas undergo transformation to diffuse large B-cell lymphoma (DLBCL). ${ }^{6}$ Although uncommon, this diagnosis explains all of the patient's findings.

To further evaluate for neurolymphomatosis, an FDG-PET scan was ordered. FDG-PET is the most sensitive and specific imaging modality in detecting lymphoma; however, other inflammatory or infectious causes can be FDG-PET avid. Tissue pathology remains the gold standard in diagnosing lymphoma and is the only way to differentiate between low-grade vs DLBCL, which has treatment and prognostic implications.7 Nerve biopsy is important in diagnosing amyloidosis, inflammatory disorders, infections, and neurolymphomatosis. Targeted fascicular biopsy should be considered in rapidly progressive neuropathies with electrophysiologic or radiographic evidence of disease. ${ }^{8}$ PET CT showed moderate brachial plexus hypermetabolism. MRI of the brachial plexus was obtained to assist in biopsy planning, which demonstrated T2-hyperintense enlargement of both plexi with peripheral enhancement (figure $2, \mathrm{~B}$ and C). The patient underwent biopsy of the right lateral cord and radial nerve. Initial radial nerve pathology demonstrated lymphoplasmacytic lymphoma with large lymphoid cells, but was insufficient for DLBCL. The samples sent from the right lateral cord, however, demonstrated lymphocytes with cellular markers consistent with DLBCL (figure 2, D-G).

The question remained as to whether the patient ever had LD, given negative repeat serology. RT-PCR for B burgdorferi was performed on the remaining skin biopsy, which was positive. Collectively, this indicates that the patient did have an acute, disseminated LD infection during his initial admission, which manifested with skin lesions and facial palsy.

\section{Discussion}

This case illustrates several important points. First, LD CSF AI is very sensitive for neuroborreliosis, but must be 


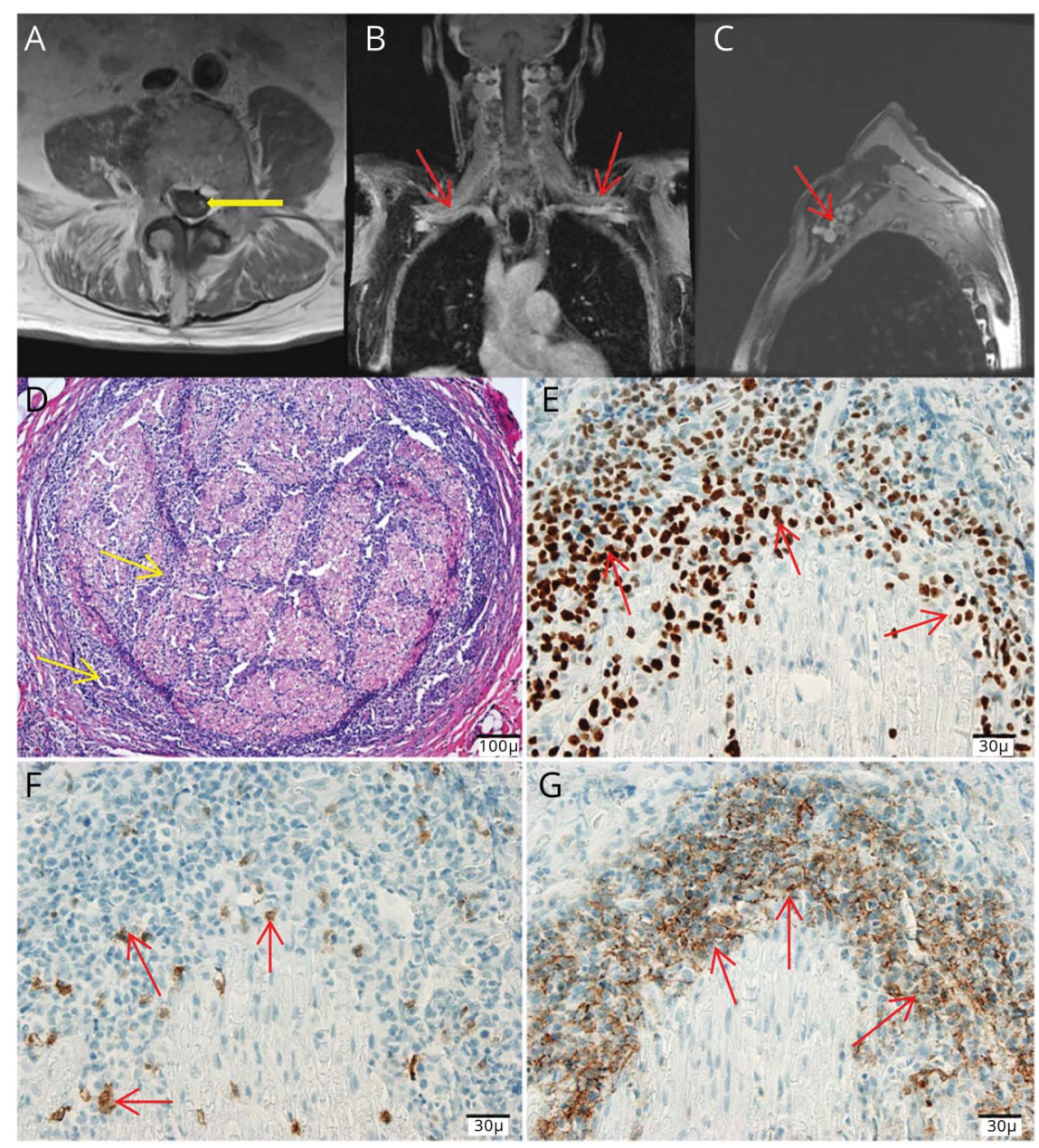

T1 postgadolinium MRI of lumbar spine demonstrates focal enhancement (yellow arrow) and thickening of nerve roots at filum terminale and L5 (A). Postgadolinium coronal LAVA Flex Water MRI (B) and left sagittal spoiled gradient recalled acquisition MRI of brachial plexi (C). Diffuse enlargement of bilateral plexi is seen along with associated peripheral enhancement (red arrows). Transverse paraffin hematoxylin \& eosin section demonstrates diffuse and dense mononuclear cell infiltrate in the endoneurium and perineurium ( $D$, yellow arrows). Immunohistochemical preparations for PAX-5 (E), CD3 (F), and CD20 (G) highlight the B-cell predominance in the lymphocyte infiltrate (red arrows). The immunophenotypic profile supports the diagnosis of diffuse large B-cell lymphoma. interpreted appropriately. The patient's initial facial palsy was likely due to neuroborreliosis, as the patient met the CDC criteria, and had a rash that tested positive by RT-PCR for $B$ burgdorferi. The positive LD CSF AI documented 9 months later likely represented persistent intrathecal antibody production after adequate treatment-an important point for clinicians to consider. ${ }^{3}$ Importantly, while CSF analysis is not required to establish neuroborreliosis in symptomatic seropositive patients, it may be helpful in select, clinically confounding cases. ${ }^{9}$

Notably, our patient's repeat serology was negative. Failure to seroconvert has been reported with early initiation of treatment during acute infection. ${ }^{10}$ Rare cases of neuroborreliosis with a positive LD CSF AI result, yet negative serum serology has been reported in otherwise healthy individuals and in patients with acquired humoral deficiency. ${ }^{11}$ In this case, the repeat negative serologic result is likely due to dissipation of the IgM antibodies, while the lack of IgG seroconversion could be due to acquired humoral deficiency from rituximab.
The second teaching point is that the emergence of multifocal peripheral neuropathies with or without pain in a patient with WM should prompt the consideration of neurolymphomatosis. Whereas neurolymphomatosis can rarely be caused by WM, DLBCL is the most common cause, and so transformation should be considered in these cases. Nevertheless, the diagnosis can be difficult to make and may be delayed by several years. ${ }^{12}$

\section{Treatment and follow-up}

The patient was treated successfully with high-dose methotrexate, rituximab, temozolomide, and ibrutinib. He experienced a relapse within a year, however, and eventually died of an opportunistic infection.

\section{Study funding}

No targeted funding reported.

\section{Disclosure}

The authors report no disclosures. Go to Neurology.org/N for full disclosures. 
Appendix Authors

\begin{tabular}{lll}
\hline Name & Location & Contribution \\
\hline $\begin{array}{l}\text { Benjamin Cox, } \\
\text { MD }\end{array}$ & $\begin{array}{l}\text { Mayo Clinic, } \\
\text { Rochester, MN }\end{array}$ & $\begin{array}{l}\text { Composed manuscript and } \\
\text { figures }\end{array}$ \\
\hline $\begin{array}{l}\text { Michelle } \\
\text { Mauermann, } \\
\text { MD }\end{array}$ & Mayo Clinic, & $\begin{array}{l}\text { Manuscript editing, revision for } \\
\text { intellectual content }\end{array}$ \\
\hline Elitza Theel, PhD & Mayo Clinic, & Manuscript editing, \\
& Rochester, MN & $\begin{array}{l}\text { revision for intellectual } \\
\text { content editing }\end{array}$ \\
\hline $\begin{array}{l}\text { Michel } \\
\text { Toledano, MD }\end{array}$ & Mayo Clinic, & $\begin{array}{l}\text { Manuscript editing, revision for } \\
\text { intellectual content }\end{array}$ \\
\hline
\end{tabular}

\section{References}

1. Centers for Disease Control and Prevention. Recommendations for test performance and interpretation from the second National Conference on Serologic Diagnosis of Lyme disease. Morb Mortal Wkly Rep 1995;44: 590-591.

2. Clark JR, Carlson RD, Sasaki CT, Pachner AR, Steere AC. Facial paralysis in Lyme disease. Laryngoscope 1985;95:1341-1345.
3. Theel ES, Aguero-Rosenfeld ME, Pritt B, et al.. Limitations and confusing aspects of diagnostic testing for neurologic Lyme disease in the United States. J Clin Microbiol 2019;57:01406-01418.

4. Lantos P, Rumbaugh J, Bockenstedt L, et al. Draft Clinical Practice Guidelines by the Infectious Diseases Society of America (IDSA), American Academy of Neurology (AAN), and American College of Rheumatology (ACR). 2019 Guidelines for the Prevention, Diagnosis and Treatment of Lyme Disease. Arlington, VA: Infectious Diseases Society of America; 2019.

5. Simon L, Fitsiori A, Lemal R, et al. Bing-Neel syndrome, a rare complication of Waldenström macroglobulinemia: analysis of 44 cases and review of the literature: a study on behalf of the French Innovative Leukemia Organization (FILO. Haematology 2015;100:1587-1594.

6. Jimenez C, Alonso-Alvarez S, Alcoceba M, et al. From Waldenstrom's macroglobulinemia to aggressive diffuse large B-cell lymphoma: a whole-exome analysis of abnormalities leading to transformation. Blood Cancer J 2017;7:e591.

7. Tomita M, Koike H, Karagashira Y, et al. Clinicopathological features of neuropathy associated with lymphoma. Brain 2013;136:2563-2578.

8. Berini SE, Dyck PJB. The utility of nerve biopsy in carefully selected patients in modern neuromuscular practice. Muscle Nerve 2019;59:635-637.

9. Moore A, Nelson C, Molins C, Mead P, Schriefer M. Current guidelines, common clinical Pitfalls, and future directions for laboratory diagnosis of Lyme disease, United States. Emerg Infect Dis 2016;22.

10. Aguero-Rosenfeld M, Nowakowski J, Nadelman RB, Bittker S, Wormser GP. Evolution of the serologic response to Borrelia burgdorferi in treated patients with culture-confirmed erythema migrans. J Clin Microbiol 1996;34:1-9.

11. Knudtzen FC, Andersen NS, Jensen TG, Skarphedinsson S. Characteristics and clinical outcome of Lyme neuroborreliosis in a high endemic area, 1995-2014: a retrospective cohort study in Denmark. Clin Infect Dis 2017;65:1489-1495.

12. Baehring JM, Damek D, Martin EC, Betensky RA, Hochberg FH. Neurolymphomatosis. Neuro-Oncology 2003;5:104-115.

\section{COVID-19 and Neurologic Disease: Call for Papers!}

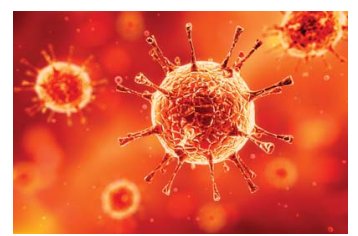

The editors of Neurology are interested in papers that address the neurological aspects of COVID-19 infection and challenges to the management of patients with chronic neurological conditions who have, or are at risk for, the infection. Relevant papers that pass initial internal review will undergo expedited peer review and online publication. We will consider papers posted in preprint servers.

Submit observational studies and clinical trials as Articles and case series and case reports under the Clinical/Scientific Notes category to https://submit.neurology.org/ today!

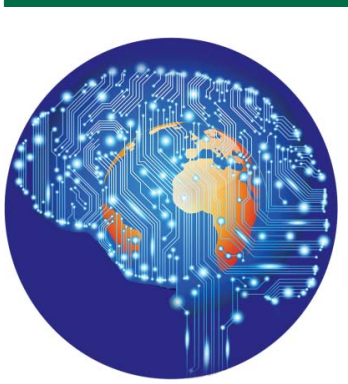

\section{Practice Current: An interactive exchange on controversial topics}

Share your own best practices.

Read commentary with expert opinion.

Explore results on an interactive world map.

NPub.org/NCP/practicecurrent

Neurology ${ }^{\circledR}$ Clinical Practice 


\section{Neurology}

\section{Clinical Reasoning: Multifocal neuropathies in a patient with Waldenstrom macroglobulinemia and prior borreliosis}

Benjamin C. Cox, Michelle L. Mauermann, Elitza S. Theel, et al.

Neurology 2020;95;44-48 Published Online before print June 11, 2020

DOI 10.1212/WNL.0000000000009741

This information is current as of June 11, 2020

\section{Updated Information \& Services}

References

Subspecialty Collections

Permissions \& Licensing

Reprints including high resolution figures, can be found at: http://n.neurology.org/content/95/1/44.full

This article cites 10 articles, 1 of which you can access for free at: http://n.neurology.org/content/95/1/44.full\#ref-list-1

This article, along with others on similar topics, appears in the following collection(s):

Bacterial infections

http://n.neurology.org/cgi/collection/bacterial_infections Cranial neuropathy

http://n.neurology.org/cgi/collection/cranial_neuropathy

Hematologic

http://n.neurology.org/cgi/collection/hematologic

Nerve tumor

http://n.neurology.org/cgi/collection/nerve_tumor

Peripheral neuropathy

http://n.neurology.org/cgi/collection/peripheral_neuropathy

Information about reproducing this article in parts (figures,tables) or in its entirety can be found online at:

http://www.neurology.org/about/about_the_journal\#permissions

Information about ordering reprints can be found online:

http://n.neurology.org/subscribers/advertise

Neurology ${ }^{\circledR}$ is the official journal of the American Academy of Neurology. Published continuously since 1951, it is now a weekly with 48 issues per year. Copyright (O) 2020 American Academy of Neurology. All rights reserved. Print ISSN: 0028-3878. Online ISSN: 1526-632X.

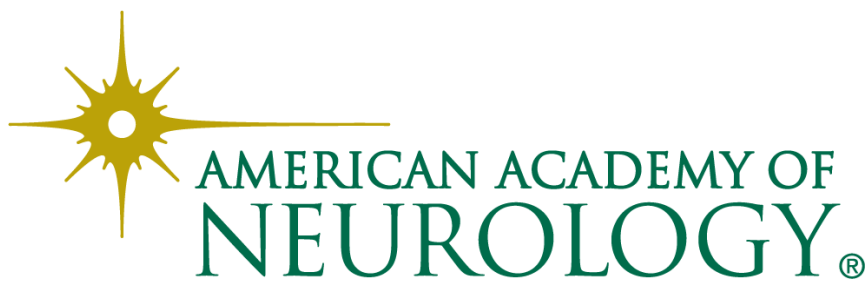

